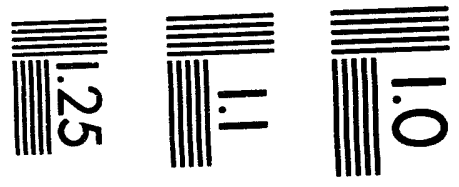

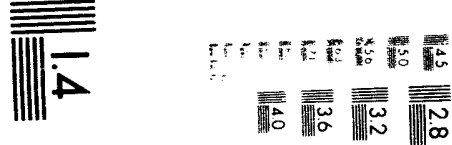

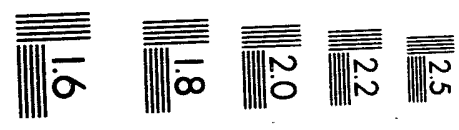



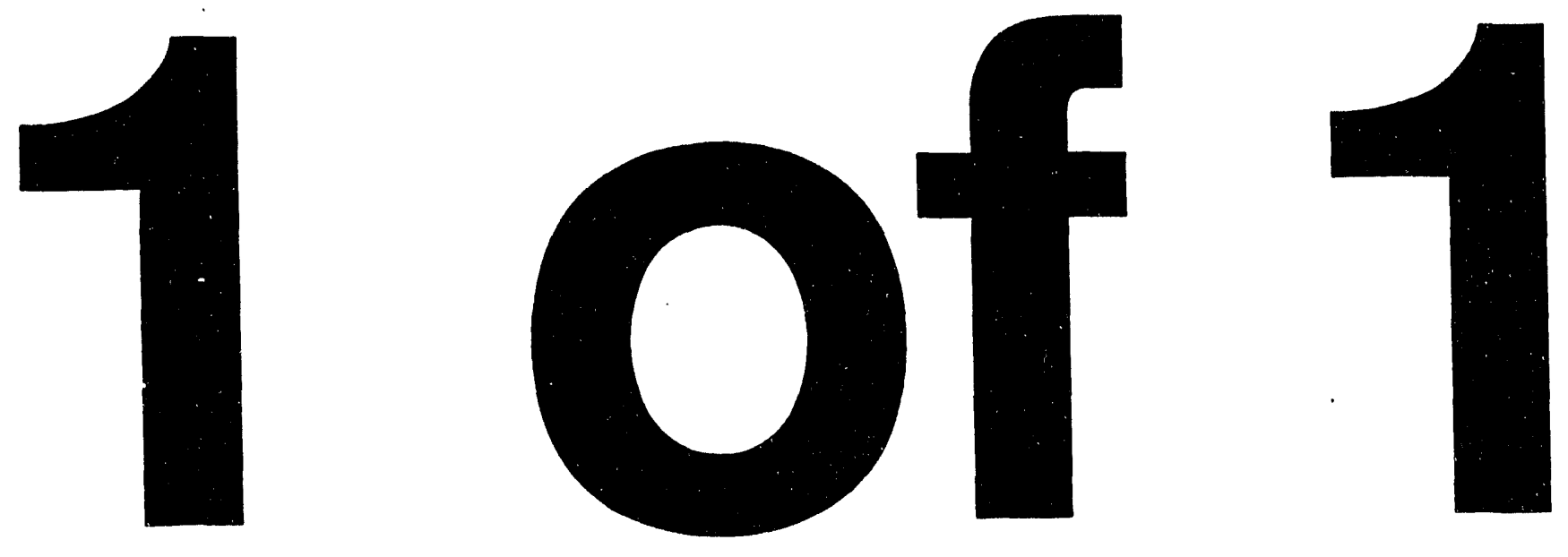


\title{
Precision Operation of the Nova Laser for Fusion Experiments
}

\author{
J. A. Caird, R. B. Ehrlich, G. L. Hermes, O. L. Landen, \\ C. W. Laumann, R. A. Lerche, J. L. Miller, J. E. Murray, \\ N. D. Nielsen, H. T. Powell, M. C. Rushford, R. L. Saunders, \\ C. E. Thompson, P. J. Van $A$ rsdall, C. S. Vann and T. L. Weiland
}

This paper was prepared for submittal to the 11th International Workshop on Laser Interaction and Related Plasma Phenomena Monterey, CA

October 25-29, 1993

February 1994

This is a preprint of a paper intended for publication in a joumal or proceed ings. Since changes may be made before publication, this preprint is made available with the understanding that it will not be cited or reproduced without the permission of the author. 


\section{DISCLAIMER}

This document was prepared as an account of work sponsored by an arency of the United States Government. Neither the United States Government nor the Unlversity of Callfornia nor any of their employ. ees, makes any warranty, expreas or implled, or aseumea any legal liability or responsibility for the sccuracy, completeness, or usefuliness of any information, apparatus, product, or process disclosed, or represents that its use would not infringe privately owned rights. Refer. ences herein to any specific commercial products, process, or service bj' trade name, irademark, manufacturer, or otherwise, does not neces. sarlis constltute or imply its endorsement, recommendatlon, or favor. ing by the United States Governmont or the University of Callfornia. The views and opinions of authors expresed herein do not necesanily state or reflect those of the United States Government or the University of California, and shall not be used for advertising or product en. dorsement purposes. 


\title{
PRECISION OPERATION OF THE NOVA LASER FOR FUSION EXPERIMENTS ${ }^{\star}$
}

\author{
J.A. Caird, R. B. Ehrlich, G.L. Hermes, O.L. Landen, C.W. Laumann, R.A. Lerche, \\ J.L Miller, J.E. Murray, N.D. Nielsen, H.T. Poweil, M.C. Rushford, R.L. Saunders, \\ C.E.Thompson, P.J.VanArsdall, C.S. Vann, and T.L.Weiland \\ Lawrence Livermore National Laboratory \\ Livermore, CA 94551-0808
}

Nova is a neodymium glass laser consisting of 10 amplifier chains that are driven from a single master oscillator. The $105 \mu \mathrm{m}$ wavelength input pulseshape is designed so that gain saturation in the amplifiers, combined with frequency conversion in KDP crystals yields the desired $0.35 \mu \mathrm{m}$ output pulseshape. In order to improve the reproducibility of experiments it was necessary to make substantial improvements in both output power balance and in pointing of the 10 beams to inertial confinement fusion targets. The required improvement in precision was estimated to be a factor $\mathrm{cf} 3$ in both power balance and pointing [1]

Improved power balance required several upgrades to Nova. Among these were (1) sensor upgrades to improve laser diagnostic measurement accuracy, (2) development of a new technique to improve pulse synchronization on target, (3) installation of regulated high voltage power supplies to improve gain stability, and (4) development of new techniques to allow compensation for differences in harmonic conversion efficiency and in gain saturation rates of the 10 Nova beamlines.

Among the sensor upgrades, we developed and installed incident beam diagnostics (IBDs) which accurately measure the $0.35 \mu \mathrm{m}$ power and energy for target experiments [2] The IBDs use a full-aperture sample of each beam produced by a $1 \%$ back reflection from a partial antireflection coating on each final focusing lens. The sensitivities of the IBDs are determined with calibration shots fired into calorimeters on the opposite target chamber wall By swapping calorimeters we determined that the relative IBD calibration accuracy was better than $3 \%$ rms

In order to improve pulse synchronization we developed a method which uses x-ray streak cameras to monitor arrival times of 100 ps pulses on a gold foil at target chamber center [3]. Initial measurements indicated timing differences of $30 \mathrm{ps}$ rms. Proper adjustment

*This work was performed under the auspices of the U.S. Department of Energy by the Lawrence Livermore National Lahoratory under contract number W-7405-ENG-48. 
of optical delays reduced these differences to less than $10 \mathrm{ps} \mathrm{rms}$, sufficient to permit power balance within desired specifications for all pulseshapes currently in use on Nova

Given precision beam synchronization and gain stability, the primary causes of power imbalance on target are beam-to-beam differences in net gain, and trequency conversion efficiency Independent control of the input energy to each beamline has always been used to produce equal energy on target. Differences in net frequency conversion efficiency, however, can be as high as $20 \%$ (largely due to differences in transmission of the debris shields), and differences of this magnitude in $1 \mu \mathrm{m}$ output energy produce large differences in pulseshape distortion due to gain saturation. Differences in pulseshape distortion can be reduced, however, if the lateral beam area is varied in proportion to the required $1 \mu \mathrm{m}$ output power and energy so that the $1 \mu \mathrm{m}$ output irradiance and fluence become the same for all beams We have found that differences in frequency conversion efficiency among the beams can be described by multiplicative factors that are independent of $1 \mu \mathrm{m}$ drive irradiance. Consequently, while frequency conversion alters the pulseshape, it makes exactly the same alteration for each heam so that power balance is mamtained. We find that simultaneous adjustment of input energies and heam areas produces adequate power halance on target for most pulseshapes currently in use on Nova [3].

At very high output energies we find that beam-to beam differences in gain saturation rates become noticeable. These arise from differences in the distribution of gain and loss in the amplifier chains. We have found that adjustment of the gain in the most heavily saturated amplifiers allows us to compensate for these differences, and produce equal gain saturation rates up to the highest output energies available on Nova Using a combination of these techniques we are able to reduce power imbalance to less than $10 \% \mathrm{rms}$ in the foot and $5 \%$ rms at the peak of shaped pulses with peak to foot contrast ratios up 10101 , and output energies up to $40 \mathrm{~kJ}$ at $035 \mu \mathrm{m}$

Pointing accuracy on Nova is limited by subaperture beam sampling, and pump induced beam steering, among other things. We established a number new procedures that reduced short term variability, and found that the residual pointing offsets are relatively stable over long periods of time. We developed techniques to measure these offsets precisely, and then apply corrections to the aim points after beam alignment Residual pointing errors were reduced to $30 \mu \mathrm{m}$ rms using these techniques, meeting our goal for precision operations [4]

\section{REFERENCES}

1 National Academy of Sciences, Second review of the Department of Energy's Inertial Confinement Fusion Program. Final Report, National Academy Press, Washington, DC (1990)

2. C. W. Laumann, J. L. Miller, et. al, "Laser diagnostics development for Precision Nova, ICF Quarterly Report, 4 (1), pg. 1, Lawrence Livermore National Laboratory. Livermore, CA, UCRL-LR-105821-94-1 (1994)

3 J A. Caird, et. al., "Precision Nova power balance," ibid, pg 10

4 J E Murray, et al, "Precision beam pointing," ibid, pg 18 

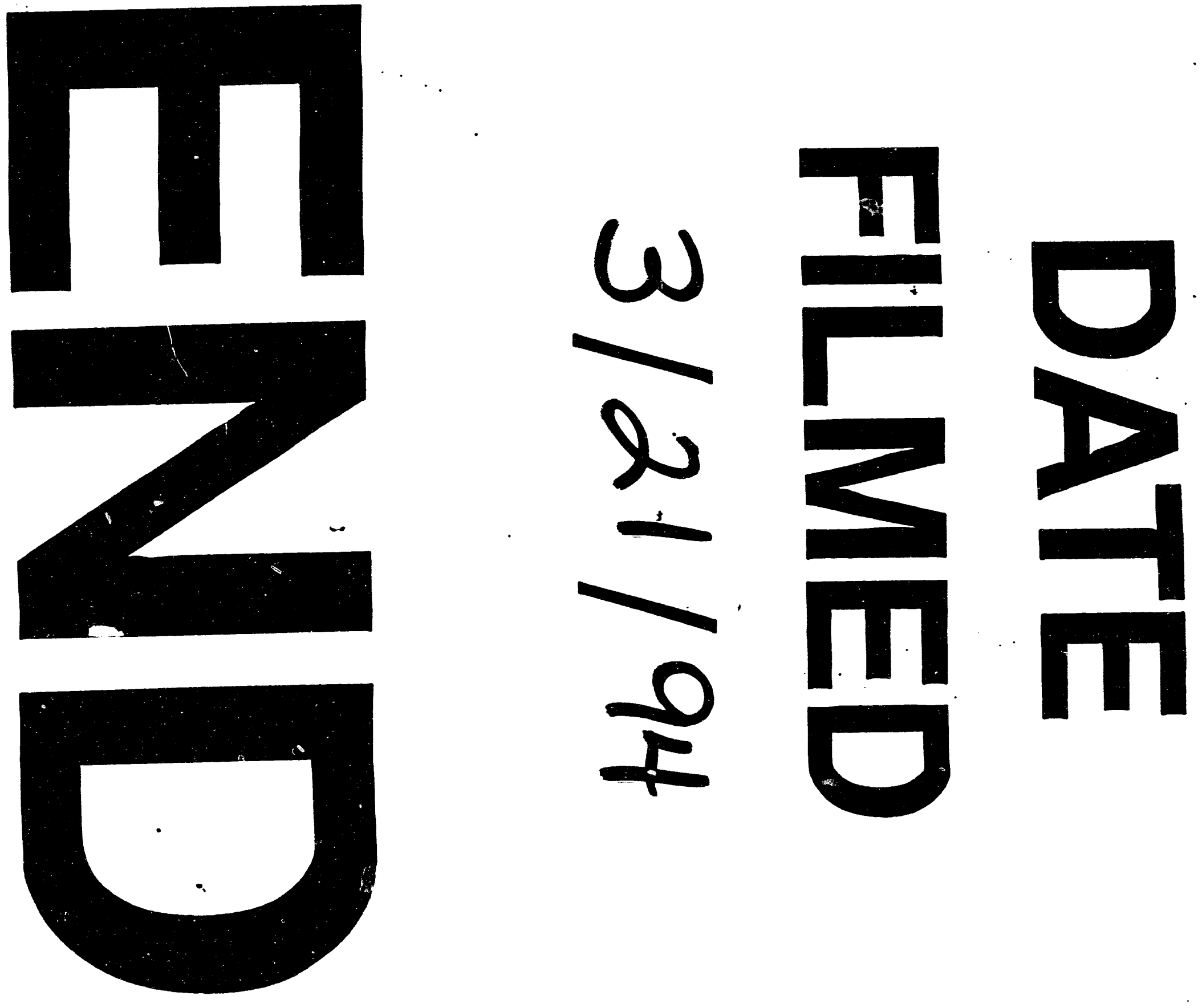


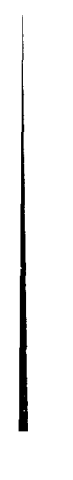

